\title{
O TEMPO VIVIDO NA PERSPECTIVA FENOMENOLÓGICA DE EUGĖNE MINKOWSKI
}

\author{
Virginia E. Suassuna Martins Costa \\ Marcelo Medeiros
}

\begin{abstract}
RESUMO. Este artigo tem como objetivo abordar as concepções de tempo assimilado ao espaço e de tempo vivido, especificando seus elementos estruturais e os fenômenos a eles relacionados, com base na perspectiva de Eugène Minkowski. Para tal, evidencia algumas conceituações a respeito do tempo em Santo Agostinho e em Henry Bergson, assim com alguns aspectos biográficos de Minkowski, que contribuíram para a compreensão a respeito do fenômeno tempo. Como meta, pretende oferecer subsídios para a reflexão dos profissionais de saúde no encontro clínico.
\end{abstract}

Palavras-chave: Tempo vivido; espaço; Minkowski.

\section{THE LIVED-TIME IN THE PHENOMENOLOGICAL PERSPECTIVE OF EUGĖNE MINKOWSKI}

\begin{abstract}
This article has the objective to deal about the conceptions of time assimilated with the space and the lived time, specifying its structural elements and related phenomena, based on Eugène Minkowski's perspective. For this, it is evidenced some concepts related to time in Saint Augustin and in Henry Bergson, as well as some Minkowski's biographic aspects that have contributed for understanding about time's phenomenon. As a goal, this paper intends to offer subsidies for the reflection by health professionals on clinic meeting.
\end{abstract}

Key words: Lived-time; space; Minkowski.

\section{EL TIEMPO VIVIDO EN LA PERSPECTIVA FENOMENOLÓGICA DE EUGËNE MINKOWSKI}

RESUMEN. Este artículo tiene el objetivo de tratar sobre los conceptos del tiempo asimilados al espacio y del tiempo vivido, especificando sus elementos estructurales y fenómenos relacionados, embasados en la perspectiva de Eugène Minkowski. Para esto, se evidencia algunos conceptos relacionados con el tiempo en Santo Agostinho y en Henry Bergson, así como los aspectos biográficos de Minkowski que han contribuido para entenderse sobre el fenómeno del tiempo. Como meta, este artículo se propone a ofrecer subsidios a la reflexión por los profesionales de salud en el encuentro clínico.

Palabras-clave: Tiempo vivido; espacio; Minkowski.

Ao falar de tempo na vida cotidiana, instintivamente olha-se o relógio ou o calendário, como se o tempo se resumisse ao "tempo assimilado ao espaço". A forma como o tempo cronológico tem sido "vivido" e experienciado na sua "velocidade" e "extensibilidade", que não interferem no tempo marcado pelo relógio (Forghieri, 1993), não tem sido objeto de reflexão dos profissionais de saúde. Em uma entrevista neurofisiológica, por exemplo, indagam-se aos pacientes aspectos mais relacionados ao seu passado - quando andou, falou, deixou de "molhar a cama" - mas pouco se investiga como esses aspectos interferem no seu presente e na sua perspectiva temporal orientada para o futuro (Augras, 1986).

A esse respeito também se posiciona Remen (1993), ao afirmar que "uma visão restrita de tempo pode igualmente diminuir a compreensão da importância e o significado de eventos e impedir uma total avaliação sobre a natureza da saúde e da doença" (p.133). Para esse teórico, como o tempo humano é

* Psicóloga. Mestre em Educação. Professora da Faculdade de Psicologia da Universidade Católica de Goiás, Goiânia-GO. Doutoranda em Ciências da Saúde .

\# Doutor em Enfermagem. Professor Associado da Faculdade de Enfermagem da Universidade Federal de Goiás, Goiânia-GO. 
imediato e de longo alcance, a melhora da saúde exige uma percepção flexível e acurada dele. Para Remen (1993), fatores anteriores aos quinze minutos de uma consulta, além de importantes para a compreensão dos sintomas, podem ser afetados por muitos anos por aquilo que ocorra durante esse rápido encontro. Remen (1993) assinala:

(...) a rápida interação médica dentro da estrutura do tempo de vida do profissional e do paciente faz com que esta abranja não apenas o tempo a longo prazo, mas também uma dimensão de tempo inteiramente diferente, a dimensão da qualidade (...) a visão de tempo materialista ignora seus aspectos qualitativos, aqueles aspectos que podemos chamar de "dimensão humana de tempo. (...) No "tempo da vida" - até quinze minutos tem qualidade -, eles são repousantes, difíceis, íntimos, belos, educativos, dolorosos e assim por diante. ( $\mathrm{p}$. 137)

Desenvolver, pois, a percepção da temporalidade, nessa perspectiva, é uma forma de ampliar as questões e preocupações peculiares ao encontro clínico. Ignorála pode levar as pessoas a perceberem problemas em relação à quantidade do tempo do profissional de saúde e à qualidade do tempo de sua consulta. Entretanto, Remen (1993, p.137) enfatiza: “os problemas na qualidade do tempo podem, na realidade, se transformar rapidamente em problemas na quantidade do tempo".

Desta forma, considerando a importância do tema e a escassez de reflexões que abordam reflexões a respeito do tempo-quantidade ou do relógio, referido como "assimilado ao espaço", e do tempo-qualidade, concernente ao "tempo vivido", este artigo parte de algumas reflexões sobre o tempo na tradição filosófica de Santo Agostinho (1987) e de Henry Bergson (1979, 1988,1999) e apresenta os elementos estruturais do tempo vivido na perspectiva de Eugène Minkowski (1965).

A relação entre esses elementos da temporalidade retrospectiva e prospectiva e a sintomatologia apresentada pelo cliente pode beneficiar o encontro clínico, ou o cuidado com o paciente, ou a situação do psicoterapeuta, no momento em que favorece o acesso a como o passado e o futuro são vividos em cada um de seus constitutivos temporais. O como torna-se um instrumento compreensivo para profissionais de saúde uma vez que indica uma reflexão teórica e uma dimensão operativo-comportamental. Na perspectiva de Minkowski (1965), existir significa viver o tempo; viver o tempo é recuperar o passado pela memória, mas é também antecipar o futuro dando ao presente uma dimensão dinâmica.

\section{O TEMPO NA PERSPECTIVA FILOSÓFICA}

Desde a antiguidade o ser humano tentou analisar racionalmente o transcorrer do tempo, procurando objetivar a sua marcha, verificando as suas repetições e relacionando-as com o espaço. O surgimento e o desaparecimento do sol a intervalos regulares permitiram ao homem estabelecer o dia e a noite, cada um com seu intervalo de atividade e repouso. Os dias foram organizados em semanas, meses e anos, marcas numéricas ainda adotadas atualmente (Forghieri, 1993). Dessa forma, ter consciência do "tempo assimilado ao espaço" significa estabelecer marcas entre dias e noites, manhãs e tardes, entre anos, meses, semanas, estações do ano, por instrumentos numéricos ou pela variação do sol no céu.

Trata-se de um tempo mecânico, marcado por regularidades que repetem o agora pontual. É o tempo do "tic-tac" do relógio, que anuncia o passar do tempo (Bicudo, 2003). É o tempo que, na sua "mesmice", pode ser vivenciado individualmente de forma angustiante, entediada, ou de outras.

A questão do tempo medido mecanicamente e vivido existencialmente na sua subjetividade levou Santo Agostinho (354-430 $\quad$ d.C.) às seguintes reflexões:

(...) não há nas nossas palavras sílabas longas e sílabas breves, assim chamadas, porque umas ressoam durante mais tempo e outras durante menos tempo? (...) Pode acontecer que um verso mais curto, lido lentamente, dure mais tempo que um mais longo lido rapidamente. (1987, p. 223-224)

Nessa acepção, o tempo não pertence, pois, às coisas do mundo, e sim, à extensão do próprio espírito, que na experiência cotidiana o vivencia e o mede, determinando sua duração com base em outras durações memorizadas. Dessa feita, Santo Agostinho (1987) consegue colocar em relevo o caráter psicológico do tempo, ou seja, o seu pertencimento à consciência.

Em Santo Agostinho (1987) há muito do que a Antiguidade pôde filosoficamente dizer acerca do tempo psicológico, ou seja, de como é experienciado naturalmente pelo espírito, o "tempo vivido". Sua influência pode ser observada em futuras reflexões a respeito da vivência do tempo, encontradas na filosofia de Henry Bergson (1979), que por sua vez, 
contribuiu decisivamente para o desenvolvimento das ideias de Minkowski a respeito dos déficits temporais como fenômeno primário de certos distúrbios psíquicos.

A filosofia de Henry Bergson (1859-1941), por sua vez, foi fruto de sua formação intelectual em uma época em que predominavam as teses materialistas, evolucionistas e deterministas. Em uma de suas obras (Bergson, 1988), preocupa-se em evitar que a realidade se reduza a fatos do positivismo e demonstra que aquilo que a ciência afirma sobre o tempo mecânico não é o dado mais concreto e imediato da experiência, mas sim, uma abstração. Sua análise do tempo envolve a noção de que o presente se estende ao passado imediato (sensório) e ao futuro (motor), tendo uma duração que simultaneamente se encontra no presente, por ele chamado de sensório-motor.

O mérito de Bergson reside, segundo Piettre (1997), na sugestão da hipótese de que o tempo da natureza não é o tempo - medida da ciência - feito de instantes, mas um tempo constituído por uma duração irreversível e rica de um futuro. Sua grande contribuição foi a distinção entre tempo vivido como experiência interna, em contraposição ao tempo cronológico, que é mensurável (Amaral, 2004).

Henry Bergson (1999) afirma que o tempo parece existir apenas na consciência, na qual passado e futuro são presentes pela memória ou pela expectativa. $\mathrm{O}$ presente é, pois, simultaneamente, sensação e movimento, e nesse sentido, o "meu presente é por essência, sensório-motor” (Bergson, 1999, p. 162). O presente consiste na consciência corporal, que experimenta sensações e se movimenta em direção a um futuro. A direção que cria o futuro diante do indivíduo é fruto do "élan vital", entendido por Bergson (1979) como o impulso original e criativo da vida, por meio do qual cada indivíduo se movimenta, evolui, garantindo-se uno em sua marcha contínua e múltipla diante de suas possibilidades.

Com essas contribuições, Minkowski (1965) afirma ter encontrado na obra de Bergson (1939) um horizonte para direcionar suas reflexões, que se estendem de forma original para um campo de pesquisa, envolvendo as manifestações psicopatológicas relacionadas às vivências do tempo, que norteiam sua tese defendida em 1926, intitulada $A$ noção do contato da realidade $e$ suas aplicações na psicopatologia.

\section{MANIFESTAÇÕES DO “TEMPO VIVIDO” NA BIOGRAFIA SE MINKOWSKI (1885-1972)}

Eugène Minkowski, proveniente de uma família judia, viveu em São Petersburgo durante sua juventude. Em Varsóvia, após estudar filosofia e matemática, foi impedido de continuar seus estudos em medicina pelo Império Russo, por participar de manifestações políticas em favor do retorno da língua polaca nos cursos universitários russos. Concluiu seus estudos em Munique, em 1908, quando retornou para a Rússia e se submeteu aos exames convencionais para graduados em outros países (Mahieu, 2007).

Sua visão fenomenologicamente orientada foi inicialmente fundamentada em sua prática, como interno em um serviço de Bleuer, em 1911 e 1912, na clínica Burghölzli, em Zurich, na qual também trabalharam Jung, Binswanger, Abraham, e por onde Lacan fizera uma breve passagem. $\mathrm{Na}$ clínica, convivia diariamente com seus pacientes, com os quais compartilhava a experiência do tempo, além de seus ideais, sensações e sentimentos, buscando vivenciar os momentos de sintonia e distonia com os comportamentos deles. Afirma que, nessa vivência, deparou-se com uma nova concepção de esquizofrenia e com a essência da psicologia da normalidade, tão incorporada a todo o seu pensamento científico, que seria incapaz de separá-los de sua própria pessoa (Minkowski, 1980). Nesse sentido, procurou desenvolver uma ciência antropológica, tendo como referência o homem, com base no inter-humano, criticando os manuais de psicopatologia clássica, que consideravam apenas uma descrição sintomatológica, sem indicações das significações dos fenômenos (Holanda, 2001).

Médico, filósofo, cientista e também militante político, Minkowski tornou-se um dos nomes mais conhecidos da psiquiatria (Mahieu, 2007). Foi considerado um dos fundadores da fenomenologia psiquiátrica, com seu colega e amigo Ludwig Binswanger, desde a realização da $63^{\mathrm{a}}$ Jornada da Sociedade Suíça de Psiquiatria, em Zurich, em 25 de novembro de 1922. No evento, apresentou um estudo intitulado Um caso de melancolia esquizofrênica, que viria a originar posteriormente sua obra intitulada " $A$ esquizofrenia: Psicopatologia dos esquizóides e dos esquizofrênicos” (Minkowski, 1980). Posteriormente, publicou outros trabalhos importantes, nenhum deles ainda traduzidos para a língua portuguesa, a saber: $L a$ schizophrénie. Psychopathologie des schizoïdes et des schizophrènes (1927), Le temps vécu (1933), Vers une cosmologie. Fragments philosophiques (1936) e o Traité de psychopathogie (1966). Todas essas obras são fruto tanto de reflexões filosóficas quanto de suas experiências como psiquiatra e como voluntário no exército francês, em 1915 e na Segunda Guerra Mundial, determinantes para seu retorno à medicina, 
particularmente à psiquiatria e à psicopatologia (Minkowski, 1965).

Nos campos de concentração, vivenciou muitos fenômenos de natureza temporal. $\mathrm{O}$ calendário objetivo, nas linhas de combate, era também substituído por um mais apropriado à situação. Os dias da semana perdiam seu significado objetivo e imediato para os sobreviventes. $\mathrm{O}$ número de jornadas transcorridas em relação às que faltavam para o retorno ao acampamento servia de referencial temporal. Momentos de monotonia, de tédio, de melancolia nas trincheiras eram vivenciados como um tempo imóvel, sem perspectiva, e, consequentemente, dificultavam a noção de duração, sucessão e continuidade do tempo, naturalmente presentes na organização cotidiana da vida. Esses fenômenos, dentre outros, foram posteriormente encontrados por Minkowski (1965) na desorganização do horizonte temporal na esquizofrenia, na qual o doente declara: "nada mais acontece, tudo parou, nem mais eu vivo. Sinto que meu coração não bate. Ele parou como meus braços que são de vidro (...) Não sei se hoje é ontem" (Augras, 1986, p. 36). Na depressão melancólica, observava o tempo imanente "Ich-Zeit" (tempo do eu) retardar-se em relação ao tempo transitivo "Welt-Zeit" (tempo do mundo), por meio da qual a inibição se instalava (Bastos, 2005).

Assim, sempre articulando aspectos vivenciais e teóricos e combinando de forma original ideias da fenomenologia de Edmund Husserl com o pensamento do filósofo Henry Bergson, Minkowski (1965) nos remete ao significado de que existir significa viver o tempo.

\section{AS ESTRUTURAS TEMPORAIS DO TEMPO: O PRESENTE, O PASSADO E O FUTURO}

Eugène Minkowski (1965) utiliza o termo devenir para referir-se ao tempo. Em concordância com Bergson (2006), define o tempo como uma "massa fluida", que se desloca de forma misteriosa e potente para frente, rumo a um futuro rico de possibilidades, e corre para frente rumo a um advir infinito, inexorável, como um rio se dirige para um oceano.

Segundo Minkowski (1965), a noção de direção do tempo nos coloca diante do fenômeno já denominado por Bergson (2005) de "élan vital". Assim como tudo na vida tem uma direção, o tempo tem o seu "élan vital", que cria o futuro antes de nós. Isto significa que ele é um instinto, uma energia que lança a vida à frente, para além do simples movimento de extensão e expansão do corpo; é a intencionalidade que orienta e direciona a vida rumo ao seu futuro. Para
Minkowski (1965), quando o "élan vital" se "apaga", o Eu perde a velocidade e a dimensão do devenir, do futuro. $\mathrm{O} \mathrm{Eu}$, não mais presente no tempo, não o administra nas suas exigências temporais e dinâmicas, da duração, da continuidade, da propulsão organizada pela "atividade e espera", "desejo e esperança”, e pela "ação ética", sustentada pela "prece".

O tempo é uma experiência primária e vital, que de tão próxima, não consegue ser exaurida pelo conhecimento, pelos sentimentos ou pela vontade, e que se encontra na existência de duas formas: como "tempo assimilado ao espaço" e como "tempo qualidade ou tempo vivido". O primeiro refere-se ao tempo do "tic-tac" do relógio, do calendário, mensurável em dias, meses e anos, medido por leis naturais de duração, sucessão e continuidade. A segunda forma pela qual o devenir se encontra na existência humana refere-se ao tempo-qualidade ou tempo vivido. Este tempo, em oposição ao primeiro, não se reduz absolutamente às dimensões espaciais mensuráveis. É o tempo vivido na introspecção, tal como aparece à consciência; é um puro tempo dado à experiência. No existir cotidiano (Forghieri, 1993), independentemente do tempo do relógio, pode-se vivenciar o tempo com "velocidades", intensidades e "extensibilidades" que se diferenciam em virtude das situações e sentimentos que delas decorrem. Instantes vivenciados em sintonia passam rapidamente; os caracterizados pelo tédio decorrem devagar; horas podem ser vivenciadas como minutos e, inversamente, minutos como horas; o passado pode estender-se até o futuro, ou este, até o presente.

O devenir é, pois, uma experiência - uma consciência que dura em uma sucessão de momentos. Ele é uma continuidade vivida. Nesse aspecto, há que enfatizar a importância da função biológica da memória e da fala, para que a duração possa dar sucessão e continuidade à unidade do eu. Afinal, a memória é um instrumento funcional do cérebro e da psique que recupera os fatos, oferecendo-lhes o caráter de duração (Bergson, 1999).

\section{O PRESENTE E O AGORA}

A organização temporal da mente não nos é dada naturalmente, haja vista as ilusões temporais das crianças e de pessoas doentes. O presente é um ato de muita complexidade, é um estado da mente, e engloba um grupo de fenômenos, incluindo o agora (Minkowski, 1965).

O devenir, com suas leis naturais, de duração, sucessão e continuidade em relação ao eu, produz o presente que mantém em si mesmo o agora, embora a 
ele não se restrinja. $O$ presente tem a função de permitir que o agora se instale. O agora é pontual, é um instante, uma parte elementar do tempo, no qual não se observam os fenômenos da duração e da sucessão. O agora, como afirma Bicudo (2003), emerge no presente e nele se finda. $O$ agora é a consciência da existência no presente. Ele é um ponto muito denso, no qual se concentra, em um instante, o último momento do passado e o primeiro momento do futuro. Ele está no presente, anima-o e o torna vivo, mas não é o presente.

O presente, por outro lado, caracteriza-se pela duração, sucessão e continuidade, e, consequentemente, não pode ter início e fim fixados. Embora semelhantes, o presente e o agora são, portanto, fenômenos temporais distintos (Bicudo, 2003).

$\mathrm{O}$ presente une o passado e o futuro, dando duração, sucessão e continuidade ao tempo vivido. Essa concepção de presente, com base na ação do tempo no espaço, foi posteriormente desdobrada nas pesquisas de Schmitz (Dias, 2007).

Por outro lado, problemas na memória podem também alterar a percepção do fenômeno de duração, sucessão e continuidade do tempo. Quando ocorre a ruptura da duração do tempo, o devenir, fluxo contínuo, de um lado, pode fragmentar-se em partes, sem comunicação e influência, sem diá-logo, sem dialética, e o tempo passa a ser vivido de forma esquizofrênica, perdendo suas partes constitutivas, fragmentando-se em momentos. De outro lado, o eu pode viver no presente, envolvido por memórias do passado, a ponto de senti-lo mais vivo que o presente atual.

\section{O PASSADO}

Em relação ao passado, Minkowski (1965) apresenta três categorias - a recordação, o remorso e o pesar - elementos capazes de abrir de novo o caminho para o futuro, se ressignificados.

A recordação, para ele, expande o presente e torna o passado revivido no aqui-e-agora, por intermédio de seus significados, que se tornam abertos para serem ressignificados; ela reforça valores e enriquece a vida. $\mathrm{O}$ remorso, caracterizado por uma recordação consciente de um passado, reconcilia-se com as exigências do devenir, e em seu caráter prospectivo, pode reparar as falhas de um tempo, eticamente projetado para a busca da ação ética. O pesar, outro fenômeno definido como uma extensão natural do passado, aplica-se a acontecimentos de menor gravidade, e se refere especialmente ao lamento pelo bem não cometido ou pelo mal materializado em um ato transgressivo, podendo também, em seu caráter prospectivo, ser ressignificado. $\mathrm{O}$ passado, para Minkowski (1965), é, pois, o tempo (já) vivido, recuperado pelas três categorias; no fenômeno da duração, é o "antes" que dá significado ao "agora" e ao "depois".

\section{O FUTURO}

Em razão do fenômeno do "élan vital" (Minkowski, 1965), que contém de forma primitiva a noção de direção do tempo, nossa vida é essencialmente orientada para o futuro. Mesmo que se reviva o passado, em forma de memórias, ou se viva no passado, essa é uma questão de reviver ou de viver em. O futuro, por seu turno, é vivido de uma maneira mais direta e imediata, pois a atenção do eu é primariamente direcionada para ele. $\mathrm{O}$ futuro garante uma perspectiva ampla e majestosa diante do eu, a qual se perde de vista e o aproxima do misterioso, tão indispensável à vida espiritual quanto o ar puro para a respiração.

Nesse sentido, há que se inquirir como o futuro pode ser vivido, sem que dele se tenha conhecimento. A resposta para a questão encontra-se relacionada aos seis fenômenos ou categorias do "élan vital" do eu, que lhe permitem viver intencionalmente o tempo, a saber: a atividade e a espera, o desejo e a esperança, a prece e a ação ética.

\section{ATIVIDADE E ESPERA}

A atividade é definida como "um fenômeno essencial da vida. Tudo que vive é ativo e tudo que é ativo vive" (Minkowski, 1965, p. 84). Ela é um dos fenômenos de natureza temporal que se encontra dirigida para o futuro ou o tempo advir, como menciona o autor, oferecendo-lhe uma vivência imediata. A atividade estende-se nessa direção naturalmente, e não pode ser fixada ou interrompida, permitindo ao eu a sensação de expansão e de identidade. É a energia vital que contém o fator duração ativa, responsável pela sequência, coerência e finalidade das ações que se sucedem no decorrer do tempo na vida do indivíduo, colocando-o diante do futuro.

No seu sentido originário, nuclear, portanto, a atividade significa a alegria imediata de viver, apesar das perdas e dos fatores de limitação. Essa categoria foi vivenciada por Minkowski (1965) quando se encontrava em situação de risco no campo de 
concentração, e paradoxalmente, experienciava a alegria de ainda estar vivo.

A atividade é, portanto, uma energia temporal, transformada em matéria que se funde com a abertura, com a potencialidade de contato com o meio ambiente, preenchendo um vazio repleto de possibilidades diante do indivíduo. É um fenômeno original e neutro, que muitas vezes parece ser suficiente em si mesmo, pois, em muitos momentos, o eu se deixa simplesmente viver, aproximando-se dos fenômenos da sintonia e do repouso, embora deles se diferencie. Em outros momentos, ela é atenção e tensão, uma energia concentrada, pronta para explodir na ação ou na sequência de ações, garantindo o ser e se identificando com a sua expansão.

Embora seja a expansão do eu no seu "élan vital", a atividade contém em si o fator de limitação dinâmica, determinada por ela mesma, no momento do contato com o meio social. Trata-se de limitação qualitativa, que não bloqueia, não retém, não aprisiona, mas protege o "élan vital" para que ele se concentre qualitativamente, e não se perca e se consuma em outras direções e metas.

O fenômeno temporal vital, que se situa no mesmo nível que a atividade mas a ela se contrapõe, é a espera. "Na espera, ao contrário, nós vivemos o tempo no sentido inverso. Nós vemos o futuro vindo em nossa direção e esperamos que o futuro se faça presente", afirma Minkowski (1965, p. 89). Na atividade, o eu é presente e dirige os eventos, ao passo que, na espera, o eu experimenta seus limites e resiste às forças alheias à força do destino. A espera é a própria atividade no momento em que se contém, mas também se encontra aberta às possibilidades ainda obscuras e impossíveis.

A espera restringe o "élan vital" pessoal a uma brusca, repentina e improvisada, parada, e por isso provoca uma grande angústia. É o próprio devenir que inverte a sua rota - em vez de ir para diante, vai para trás. Ela suspende a atividade e fixa o sujeito de forma angustiante. Pode-se afirmar que, nesse fenômeno, todo o futuro, o advir concentrado, está fora do indivíduo e cai sobre ele como uma massa poderosa e hostil, na tentativa de mumificá-lo.

Se a atividade provém da alegria de viver, a espera é sempre angustiante e provoca a sensação de um morrer próximo. Em seus matizes afetivos, portanto, atividade e espera são claramente opostas.

Na espera, o "élan vital" paralisa-se por não mais ter domínio e controle sobre o tempo, e torna-se vítima do advir, que se dirige contra o eu, suspendendo momentaneamente a vida, que se fragmenta em uma sucessão de instantes, perdendo a dimensão da duração.

Enfim, se na atividade o eu se estende nos espaços vazios, tornando-se quase um todo, na espera o eu é reduzido à mais simples expressão, ficando sob ameaça de ser engolido, tornando-se quase nada.

Não obstante, à medida que ambas as categorias se equilibram, uma a serviço da outra, como quando a espera se aproxima da essência da atividade, exprimindo uma tensão-abertura-prontidão em relação a um possível evento dado, como oportunidade-apelochamada, elas promovem a possibilidade de o eu atuar no mundo de forma adequada.

\section{DESEJO E ESPERANÇA}

O desejo e a esperança, outros dois momentos do tempo, embora situados na mesma direção do tempo, rumo ao advir, estão para além da atividade e da espera, colaborando para sua construção. Essas duas categorias retiram o eu do contato imediato, favorecendo o contato com o mediato, alargando a perspectiva do futuro diante de si mesmo, e afirmam que há sempre algo a desejar e a esperar da vida, do futuro. $\mathrm{Na}$ atividade, portanto, o eu é carregado para o futuro de forma mais imediata e contínua, ao passo que, no desejo, é conduzido de forma mediata, distanciando-se do agora e permitindo repouso ao próprio presente. Nesse sentido, essas duas categorias relacionam-se diretamente com o fenômeno mais longínquo, em todas as direções, em todos os sentidos, oferecendo possibilidades para a atividade realizar a sua obra.

Sem o desejo, o eu perde sua força, coragem, intimidade consigo mesmo, e promove um grande vazio existencial que vai engolindo a vida e o tempo e degradando o espaço.

À medida que o desejo abre, de forma mais ampla, o futuro diante do eu, supera a esfera particular do que se possui, indo sempre além. Só se pode desejar o que não se possui, o que gera o verdadeiro significado da vida. Dessa forma, há mais satisfação no desejo e na esperança do que na realização, na conquista, na posse, porque ambos possuem horizontes infinitos. Na realização, a obra fecha-se às demais possibilidades (Minkowski, 1965).

O desejo, mais especificamente, caracteriza-se por ser mais fixo e duradouro que a atividade, visto que esta, pela sua própria natureza dinâmica, não pode ser fixada, a não ser por um tempo de parada sob a forma do eu existo (Minkowski, 1965). Tão essencial à vida como a atividade, o desejo pode ser comparado à 
forma que anima a matéria, pois sem a forma a matéria se perderia, assim como sem o direcionamento do desejo a vida explodiria ou implodiria. Por outro lado, o desejo, em algumas situações, pode ser mais episódico que a atividade o eu pode não apresentar clareza em relação aos seus desejos.

Finalmente, o desejo pode ser também definido como uma sombra projetada pela atividade para o interior do eu, como uma representação vivida dela mesma. Nesta dimensão, portanto, parece que o desejo está mais intimamente ligado ao eu íntimo, ao meu, do que ao eu da atividade, e parece ser uma faculdade adicionada à atividade no curso da evolução dos seres humanos (Minkowski, 1965).

A categoria temporal esperança, em particular, por seu turno, é vivenciada pelo eu na mesma direção da espera, na direção futuro-presente e não na direção do presente-futuro, embora não seja um prolongamento linear da espera (Minkowski, 1965). Ao passo que o desejo contém a atividade dentro de si, a esperança nos libera da ansiedade e do aperto da espera; ela desvia o contato com o presente imediato e dirige o olhar do eu para uma instância mais distante do que aquela que se sucede imediatamente. $\mathrm{Na}$ verdade, não existe esperança de algo no instante presente ou naquele que imediatamente o sucede, mas de alguma coisa no futuro. "Quando eu tenho esperança, eu espero a realização daquilo pelo qual tive esperança", assevera Minkowski (1965, p. 103).

A esperança é a característica que permite ao advir se apresentar à nossa frente, como um horizonte de possibilidades que, por si só, é mais fascinante do que a própria conquista. Aparentemente, a esperança pode dirigir-se ao passado, como, por exemplo, na expressão "tomara que ontem nada tenha acontecido ao meu amigo" em relação a um acidente ferroviário ainda não esclarecido pelas notas oficiais. Trata-se de um passado que se parece mais com o futuro, no qual há a espera das notícias, há a esperança de uma revelação futura, que mesmo pertencendo a um passado, será desvelada, dando espaços a sentimentos de alegria ou de dor no futuro.

Como elemento constitutivo e construtivo do advir, a esperança situa-se além do otimismo e do pessimismo, produzindo um sentimento como na expressão "dar a volta por cima", e se faz presente, mesmo depois de inúmeras derrotas. A esperança, como o desejo, encontra-se tanto ou mais intimamente ligada ao eu, permitindo-lhe refugiar-se para contemplar a vida na sua extensão. Resistente ao próprio otimismo e ao pessimismo, a esperança vai além de ambos, é uma emoção contemplativa e construtiva porque, sem ela, o advir mediato não existiria.

\section{PRECE E AÇÃO ÉTICA}

Para além das categorias descritas, encontram-se as duas últimas, relacionadas com a prece e a ação ética. A esperança transporta o eu no tempo em direção à eternidade, e, nesse momento, ela se identifica com a prece. É ela que dá consistência à própria espera e a resgata da passividade. O agora da espera torna-se operante e se ilumina na esperança, resgatando e significando os seus insucessos e decepções (Minkowski, 1965).

Como todos os outros fenômenos vitais, a prece tem sua origem na afirmação da vida, embora surja em circunstâncias nas quais ela aparece ameaçada, como na presença da morte, nos desastres físicos ou morais, que ameaçam o eu. Nessas situações, a esperança parece ser insuficiente para confortar o eu, promovendo o seu movimento em direção à prece. É o momento em que o eu se eleva para além de si mesmo, daquilo que o rodeia, em direção a um horizonte infinito, para uma esfera além do tempo e do espaço, cheia de grandeza, claridade e mistério (Minkowski, 1965).

Destarte, refletir sobre a prece equivale, no fundo, a falar da fé em uma divindade com a qual o eu entra em diálogo. Entretanto, como categoria minkowskiana, a prece não se reduz a uma recitação quotidiana de orações e de rituais e, pela sua natureza intrínseca, é um fenômeno excepcional, que não necessita ser praticada diariamente, pois está para além desse aspecto: "É a presença do fator futuro na prece que a distingue dos outros estados místicos ou religiosos, como a oração, meditação ou êxtase" (Minkowski, 1965, p. 107). Mesmo que se refira a um pedido de perdão por algo cometido no passado, ela se dirige para o futuro. Ela consiste na elevação do espírito, de forma solene, sagrada, motivada por situações existenciais de diversas naturezas, e nesse sentido pode ser acessada até por aqueles que duvidam da existência de Deus. Ela é uma interiorização totalmente vivida, na qual o eu se depara com o ambiente em transformação e com o que mais de profundo existe em si mesmo (Minkowski, 1965).

$\mathrm{O}$ desejo e a esperança superam a atividade e a espera, transformando o imediato no mediato; a prece, porém, vai ainda mais adiante, transformando o mediato em absoluto (Minkowski, 1965). Na direção do absoluto, vai tão longe que o eu não saberia como ir mais além. A prece dirige-se para um horizonte tão 
distante, que parece estar fora do tempo e do espaço, permanecendo, paradoxalmente, tão perto do eu, como se este pudesse por ela ser transformado. A prece nasce da parte mais profunda do eu, e lhe permite ir além de si mesmo, em direção à sua parte mais profunda, além do "meu”. A prece é, nesse aspecto, uma exteriorização e interiorização totalmente vivida pelo eu, simultaneamente oferecendo-lhe o significado primordial da abstração. Ela conecta o eu com o que ele persegue durante toda a vida, o "conhece-te a ti mesmo", constituindo o estágio mais elevado e supremo em relação às categorias compostas pelo desejo e pela esperança, uma vez que, durante a prece, o eu não somente deseja e tem esperança, mas faz muito mais - ele reza.

Por último, Minkowski (1965) identifica como o pilar principal da estrutura da temporalidade relacionada ao advir, a ação ética, por considerá-la um dos elementos constitutivos essenciais, senão o mais importante da vida e sobre o qual ela se baseia. Sem essa categoria, segundo ele, seríamos seres amorais, o que modificaria sobremaneira a vida e a abertura do futuro diante do ser humano.

A ação ética, como a prece, tem uma ressonância totalmente natural, por sua própria essência, e se encontra ao alcance de cada um de nós. Ela é a realização do que há de "humano" em nós, do que é virtualmente comum em nós, daquilo que anima toda a nossa vida (Minkowski, 1965). Ela aproxima o eu daquilo que existe de mais sublime, de mais elevado, de mais ideal nele mesmo, favorecendo o progresso efetivo da sociedade. Por meio da ação ética, ocorre uma fusão imediata entre o universo imediato e o eu que, esquivando-se dos interesses que constituem a materialidade da vida, penetra e apela para o que existe de melhor em si mesmo, em uma inspeção luminosa, tomando consciência de si mesmo.

A ação ética é a única ação que resiste ao devenir, que tenta submergir tudo à sua passagem, permanecendo sempre acompanhada de um sentimento de alegria, intimamente ligado à atividade. Alegria que não é de prazer, mas de realização do que há de mais elevado no ser humano - a ação ética, na qual o eu se recria continuamente.

Em síntese, as duas primeiras categorias, a atividade e a espera, são motivadoras e orientadoras do eu em relação ao horizonte temporal, que permanece em uma atitude atenta às solicitações, a um chamado, a uma oportunidade, dada por um evento da história; as duas seguintes, o desejo e a esperança, são aspectos que, transcendendo o tempo, permitem ao "élan vital" do eu transitar no universo dos valores sem limites, movimento que é a expressão da essência do ser, na liberdade do seu advir; e as duas últimas, a prece e a ação ética, recuperando os valores do passado antecipam o futuro, ampliam o presente, dando ao aqui-e-agora horizontes sem fim, confirmando o eu na sua existência.

\section{CONSIDERAÇÕES FINAIS}

As reflexões a respeito do tempo abordadas na perspectiva filosófica de Santo Agostinho (1987), Bergson (1979, 1988, 1999) e Minkowski (1965) incluem a concepção de "tempo assimilado ao espaço" e a do "tempo vivido", na qual o presente contém de forma singular o passado e o futuro. Santo Agostinho (1987) enfatiza elementos, como a memória e a expectativa, que atuam no presente pela atenção; Bergson (1999) define o tempo presente como sensório-motor e, finalmente, Minkowski (1965) sinaliza a existência do presente como fruto de um passado do qual surge e de um futuro para o qual se dirige por intermédio de seus elementos estruturais e do fenômeno "élan vital", que cria o futuro diante de nós.

A possibilidade de compreender o modus vivendi da temporalidade do paciente por intermédio do como o "élan vital" tem sido vivido, sua velocidade e extensão em relação ao futuro, rupturas nas partes constitutivas do passado, presente e futuro que acarretam a perda do efeito de duração de continuidade, fragmentando o tempo em momentos, dentre outros aspectos, parecem indicar uma dimensão operativo-comportamental nos elementos constitutivos da temporalidade, utilizável clinicamente.

O profissional de saúde, atento ao como passado que se faz presente pelos elementos constitutivos recordação, memória ou pesar, - poderia atuar na ressignificação de tais elementos, ampliando o futuro que se impõe diante do paciente, e desenvolver intervenções nos elementos constitutivos do futuro atividade e espera, desejo e esperança, ação ética e a prece -, proporcionando ao indivíduo possibilidades de resgate de sua função de protagonista da própria vida, tal como aponta Petrelli (1999).

Atuar de forma operativo-comportamental nos elementos do "tempo vivido" apoia-se, também, na concepção heidegeriana (Heidegger, 1981) segundo a qual cuidar, em uma perspectiva temporal, é considerar o que passou e ter paciência com o que está por vir.

Como afirma Remen (1993), um crescente número de pessoas tem acreditado na dimensão ampliada do tempo, e até mesmo em alguma forma de vida após a morte. Para ele, aquilo que a pessoa sente 
e acredita a respeito do tempo é um aspecto fundamental no seu processo de cura.

Todas essas possibilidades surgem da crença de que o tempo não é apenas uma dimensão do mundo, mas uma orientação significativa do ser; é uma construção na qual o presente não é determinado pelo passado, mas pelo horizonte futuro, com suas categorias específicas, em que o passado e o presente são vivenciados.

O tempo, embora seja a garantia da impermanência do ser no mundo, é também condição de sua existência, diante da qual somos todos responsáveis. "No decorrer de nosso existir caminhamos, a cada dia, para viver mais plenamente, assim como morrer mais proximamente", declara Forghieri (1993, p. 52).

É preciso, afirma Costa (2003), descobrir o ser-aí por detrás do sintoma, uma vez que carne, sangue e nervos são apenas uma fina camada que envolve um segredo invisível, uma estória que mora em nós. $\mathrm{O}$ paciente não é um caso, e sim uma pessoa, cuja linguagem da alma se expressa no corpo, no tempo do relógio e no tempo vivido.

\section{REFERÊNCIAS}

Agostinho, S. (1987). Confissões de magistro. $4^{\mathrm{a}}$ ed. São Paulo: Nova Cultural.

Amaral, A. E. V. (2004). O método de Rorschach e a psicopatologia fenômeno-estrutural. Estud. Psicol., 21(1), 73-81.

Augras, M. (1986). O ser da compreensão: fenomenologia da situação de psicodiagnóstico. São Paulo: Vozes.

Bastos, C. L. (2005). Depressão, cultura e temporalidade. Recuperado em 12 de março de 2007 em http://www.polbr.med.br/arquivo/art0205b.htm

Bergson, H. (1979). Cartas, conferências e outros escritos. (F. L. Silva, Trad.) Coleção Os Pensadores. São Paulo: Abril Cultural (Original publicado em 1903).

Bergson, H. (1988). Ensaio sobre os dados imediatos da consciência. (J. S. Gama, Trad.). Lisboa: Edições 70.
Bergson, H. (1999). Matéria e memória. $2^{\mathrm{a}}$ ed. (P. Neves, Trad.). São Paulo: Martins Fontes (Original publicado em 1939).

Bergson, H. (2005). A evolução criadora. (2005). $1^{\text {a }}$ ed. (B. Prado Neto, Trad.). São Paulo: Martins Fontes (Original publicado em 2004).

Bergson, H. (2006). Duração e simultaneidade. A propósito da teoria de Einstein. $1^{\mathrm{a}}$ ed. (C. Berliner, Trad.). São Paulo: Martins Fontes (Original publicado em 2006).

Bicudo, M. A. (2003). Tempo, tempo vivido e história. Bauru: EDUSC.

Costa, V. E. S. M. (2003). A fenomenologia como possibilidade de entendimento da relação médico-paciente. Em R. F. G. R. Branco (Org.), A relação com o paciente (pp. 25-32). Rio de Janeiro: Guanabara Koogan.

Dias, G. S. O corpo em mira: entrevista com Hermann Schmitz. Novos Estudos - CEBRAP, 74. Recuperado em 20 de março de 2007 em http://www.scielo.br

Forghieri, Y. H. (1993). Psicologia fenomenológica: fundamentos, métodos e pesquisa. São Paulo: Pioneira.

Holanda, A. F. (2001). Psicopatologia, exotismo e diversidade: ensaio de antropologia da psicopatologia. Psicologia em Estudo, 6(2), 29-38.

Heidegger, M. (1981). Todos nós... ninguém: um enfoque fenomenológico do social. (D. M. Critelli, Trad.). São Paulo: Moraes (Original publicado em 1922).

Mahieu, E. T. (2007). Historia de la Psiquiatria: Eugene Minkowski (1885-1972). Recuperado em 10 de março de 2007 em http://www.psicomundo.org/otros/minkowski.htm.

Minkowski, E. (1965). Il tempo vissuto. Roma: Einaude.

Minkowski, E. (1980). La esquizofrenia: psicopatologia de los esquizóides y los esquizofrênicos. Buenos Aires: Editorial Paidós.

Remen, R. N. (1993). O paciente como ser humano. São Paulo: Summus.

Petrelli, R. (1999) Para uma psicoterapia em perspectiva fenomênica existencial. Goiânia: Editora UCG.

Piettre, B. (1997). Filosofia e ciência do tempo. Bauru: EDUSC.

Recebido em 20/09/2007 Aceito em 04/09/2008

Endereço para correspondência : $\quad$ Marcelo Medeiros, Rua 1128, n. 572, Quadra 237, Lote 09; Setor Marista; CEP 74175130, Goiânia-GO, Brasil. E-mail: marcelo@fen.ufg.br 